\title{
Incidence and Predictors of Chronic Kidney Disease among Diabetes Mellitus Patients: A Retrospective Follow-Up Study at a Tertiary Health-Care Setting of Ethiopia
}

\author{
Gebiso Roba Debele (iD) \\ Mohammedamin Hajure (iD ${ }^{2}$ \\ Haileab Fekadu Wolde iD ${ }^{3}$ \\ Melaku Kindie Yenit (iD) ${ }^{3}$ \\ 'Department of Public Health, College of \\ Health Sciences, Mettu University, Mettu, \\ Ethiopia; ${ }^{2}$ Department of Psychiatry, \\ College of Health Sciences, Mettu \\ University, Mettu, Ethiopia; ${ }^{3}$ Department \\ of Epidemiology and Biostatistics, \\ Institute of Public Health, College of \\ Medicine and Health Sciences, University \\ of Gondar, Gondar, Ethiopia
}

Background: Chronic kidney disease (CKD) is one of the most common microvascular complications of diabetes mellitus (DM) and it is a major health burden worldwide. Despite the increasing trend of microvascular complications in developing countries, there is limited evidence on predictors of CKD among diabetic patients in Ethiopia. Therefore, this study was aimed to assess the incidence and predictors of CKD among DM patients.

Methods: A retrospective follow-up study was conducted among type 1 and type 2 DM patients in Southwest Ethiopia. A total of 437 newly-diagnosed diabetes patients were selected using a simple random sampling technique. Data were extracted from patients' medical records. Cox proportional hazard model was fitted and a 95\% confidence interval was used to select significant variables.

Results: Overall, $15.56 \%$ of patients developed CKD, with an incidence rate of 2.29 per 1,000 person-month $(\mathrm{PM})(95 \% \mathrm{CI}=1.79-2.93)$. Female sex $(\mathrm{AHR}=0.51,95 \% \mathrm{CI}=0.27$ 0.94) was found to be a protective factor of $\mathrm{CKD}$, while positive proteinuria (AHR=2.85, $95 \% \mathrm{CI}=1.48-5.55)$, having hypertension $(\mathrm{HTN})(\mathrm{AHR}=2.31,95 \% \mathrm{CI}=1.03-5.56)$, and highdensity lipoprotein cholesterol (HDL-C) $<40 \mathrm{mg} / \mathrm{dL}(\mathrm{AHR}=3.19,95 \% \mathrm{CI}=1.73-5.98)$ were significant predictors of CKD.

Conclusion: CKD among DM patients continues to be a significant public health problem in health-care settings of Ethiopia. The current study found being female was protective, while positive proteinuria, HTN, and HDL-C $<40 \mathrm{mg} / \mathrm{dL}$ were risk factors for $\mathrm{CKD}$. We recommend health professionals to give more attention to DM patients with the identified risk factors.

Keywords: incidence, chronic kidney disease, predictors, diabetes mellitus

\section{Introduction}

Diabetes mellitus (DM) is the most prevalent metabolic syndrome characterized by high levels of plasma glucose. ${ }^{1}$ Globally, there is a 463 million (9.3\%) prevalence of DM and it is projected to increase to 700.2 million by 2045 according to the 2019th International Diabetic Federation (IDF). ${ }^{2}$ The prevalence of DM in Ethiopia was reported to be $4.3 \% .^{2}$ The clinical importance of DM is largely due to its association with the risk of $\mathrm{CKD}^{3}{ }^{3}$ in which $30 \%$ of type $1 \mathrm{DM}$ (T1DM) and $40 \%$ of type 2 DM (T2DM) patients develop CKD throughout their life.

Due to its complexity, the pathophysiology of CKD among DM patients is still not fully explained. ${ }^{5}$ However, DM is assumed to cause CKD through renal
Correspondence: Gebiso Roba Debele Email gebisa.roba123@gmail.com 
hyperfunction due to excess glucose filtration. This will cause a blockage of tiny blood vessels of nephrons. Hence, renal injury due to blood insufficiency from clotting and progressive damage of nephrons due to deposition of end products of glucose on the basement membrane causes $\mathrm{CKD}^{6}{ }^{6} \mathrm{CKD}$ is the major microvascular complication of $\mathrm{DM}$ which is characterized by persistent albuminuria, elevated blood pressure, and progressive decline of kidney function. The kidney disease improving global outcome classified CKD into five stages based on the glomerular filtration rate (GFR), of which stage $\mathrm{V}$ is the most severe form and it needs renal replacement therapy (RRT). ${ }^{7}$ Death due to kidney disease has increased by $39.5 \%$ between 2005 and 2015 and it is ranked the 12th most common cause of death, accounting for 1.1 million deaths worldwide in $2015{ }^{8}$ Globally, the prevalence of CKD is estimated to range from $8-16 \% .^{9}$ Diabetic nephropathy was estimated to be $35.3 \%$ and $29.7 \%$ in sub-Saharan and eastern African countries, respectively. ${ }^{10}$ Studies from northern and southern parts of Ethiopia show the prevalence of CKD among DM patients to be $21.8 \%$ and $23.8 \%$, respectively. ${ }^{11,12}$

CKD is an increasing clinical and public health problem related with adverse health outcomes including end stage renal disease (ESRD), heart failure, and high costs of treatment. ${ }^{13}$ Diabetes alone contributes to $12-55 \%$ of ESRD and its incidence is 10-times higher among adults with diabetes compared to the general population. ${ }^{14}$ Due to the high costs of treatment in developing countries, most people with ESRD continue to die despite established treatment options. ${ }^{15}$ Nine of ten patients diagnosed with ESRD in Asia and more than $70 \%$ in India die within a few months due to scarce resources to get therapy. ${ }^{16,17}$ Less than $3 \%$ of ESRD cases get access to renal replacement therapy in middle and eastern Africa. ${ }^{18}$

According to different studies conducted worldwide, age, ${ }^{19}$ proteinuria, ${ }^{19} \mathrm{HDL}-\mathrm{C},{ }^{20-23} \mathrm{HTN},{ }^{23}$ and body mass index $(\mathrm{BMI})^{22,23}$ are the factors which are significantly associated with the risk of CKD among DM patients. Nonetheless, in Ethiopia, the few studies conducted on factors associated with microvascular complication of diabetes did not assess the effect of predictors on CKD independently. This might under- or overestimate the actual effect of predictors on CKD among DM patients. Thus, this study aimed to determine the incidence and predictors of chronic kidney disease among DM patients in Jimma University medical center, Southwest Ethiopia.

\section{Materials and Methods Study Setting}

The study was conducted at Jimma University Medical center. The hospital is one of the oldest public hospitals in Ethiopia located in Jimma zone, Oromia regional state, Southwest Ethiopia, which is about 352 kilometers from Addis Ababa. The hospital provides services for approximately 9,000 inpatient and 80,000 outpatient attendants per year. Besides, there are separate chronic disease follow-up clinics including diabetic clinics.

\section{Study Population and Design}

An institution-based retrospective follow-up study was conducted among T1 and T2DM patients at Jimma University medical center. All DM patients who had follow-up at the hospital and whose age is greater than or equal to 15 were our source population. Besides, all newly-diagnosed T1DM and T2DM patients who were enrolled to treatment between September 5, 2012 and August 2015 were our study population. Patients who already developed CKD at the start of the study and patients with unknown date of DM and CKD diagnosis were excluded from the study. DM was defined as fasting blood sugar (FBS) $\geq 126 \mathrm{mg} / \mathrm{dL}$ that is confirmed by repeated testing at the second visit. ${ }^{1}$ Our dependent variable was chronic kidney disease, which is defined as abnormalities of the kidney structure or function that is marked by a glomerular filtration rate (GFR) $<60 \mathrm{~mL} / \mathrm{min} /$ $1.73 \mathrm{~m}^{2}$ ) present for $>3$ months and albuminuria $>30 \mathrm{mg} / 24$ hours and history of kidney transplantation. ${ }^{7}$ The case was determined based on the clinical decision of the physician obtained from the patient's medical records. Time to CKD was the time interval in months between the diagnoses of diabetes mellitus and development of CKD. Death, being lost to follow-up and being event-free at the end of the study were considered as a censored. Lost to follow-up was defined as absence of the patients from the follow-up for one or more successive years since they last visited the diabetic clinic. $^{24}$ Diabetic retinopathy was defined as a microvascular complication of DM that is diagnosed by ophthalmoscopy or/and clinical examination by retinal specialists and then confirmed by fundus photography. ${ }^{25}$ The World Health Organization (WHO) defined BMI as a physiological factor that is measured by weight in kilograms per square of height in meters $\left(\mathrm{kg} / \mathrm{m}^{2}\right)$ and it is classified as low $\left(<18.5 \mathrm{~kg} / \mathrm{m}^{2}\right)$, normal $\left(18.5-24.9 \mathrm{~kg} / \mathrm{m}^{2}\right)$, and high $\left(\geq 25 \mathrm{~kg} / \mathrm{m}^{2}\right) .{ }^{26}$ Hypertension (HTN) was defined as an average of the first two blood pressure measurements 
taken on different days $\geq 140 / 90 \mathrm{mmHg} .{ }^{27}$ Baseline characteristic were taken from the patient's registration record at the start of the study and patients were assessed for CKD in every follow-up visit. Accordingly, data on sociodemographic, clinical, comorbidities, and physiologic characteristics were collected from patient's medical charts. All lipid profiles (HDL-C, low density lipoprotein cholesterol (LDL-C), triglyceride, and total cholesterol) were categorized for analysis based on the Mayo clinic and guidelines from the National Cholesterol Education Program. ${ }^{28,29}$

\section{Sample Size Determination and Sampling Procedure}

The sample size was determined using Schoenfeld formula ${ }^{30}$ by taking three factors significantly associated with risk of CKD from previous studies. ${ }^{19,24}$

$E=\frac{\left(\frac{Z \alpha}{2}+Z \beta\right)^{2}}{P 1 P 2(\ln H R)^{2}}$ and $n=\frac{E}{P(E)}=$ Schoenfeld formula for manual calculation.

Where $E=$ number of required events, $n=$ sample size, $H R$ is hazard ratio of selected covariates, $P 1$ is the proportion of subjects under the exposure group, $p 2=1-p 1$ and $P(E)$ is the probability of an event from a previous study.

Finally, the maximum sample size (437) was taken from the three calculated samples (Table 1). Study subjects were selected by simple random sampling technique using computer generated random numbers. The sampling frame was prepared by collecting the identification number of DM patients from the registration book.

\section{Data Collection Procedures and Quality Control}

Data were collected from the patient's intake form and follow-up charts that are routinely sent by the hospital to the follow patients. Before actual data collection, a preliminary review was conducted on a $5 \%$ sample size to evaluate the adequacy of the checklist. Variables such as family history of renal problems, behavioral factors, occupation, and adherence to treatment are not available in the record and not considered in this study. Data were collected using uniform checklists by nurses working in the hospital. Filled checklists were checked for consistency and completeness before entry.

\section{Data Management and Statistical Analysis}

Data entry was done using Epi-Data version 4.6 and then exported to $\mathrm{R}$ statistical software 3.6.1 for further data cleaning and analysis. In order to avoid misspecification of missing data mechanism, we applied sensitivity analysis to multiple imputation and a complete case analysis approach of missing data handling mechanisms. For continuous variables, mean with standard deviation (SD) for normally distributed and median with interquartile range (IQR) for non-normally distributed variables was used to describe the population. Categorical variables were described in terms of frequencies and percentages.

The cumulative incidence of CKD was calculated by taking the number of new chronic kidney diseases as the numerator and the total initial population as the denominator. Patient-months at risk of developing CKD were calculated from the baseline appointment date to either the date of events or censoring. Accordingly, incidence density was computed as the number of new cases divided by patient-months at risk.

Time to CKD was estimated using Kaplan-Meier (KM) and Log rank test to compare survival time between groups of categorical variables. Proportional hazard assumptions (PHA) were checked using cumulative log hazard plot and Schoenfeld residuals method. Variables with a $P$-value less than 0.2 from the bivariable analysis were included in the multivariable survival model. Best fitting survival model was selected based on Akaike Information Criterion (AIC) and goodness of fitness of the model was checked using Cox Snell residual plot. Finally, Cox proportional hazard was used to compute the hazard ratios and a $P$-value $<0.05$ was used to declare statistical significance.

Table I Minimum Sample Size Using Covariates Associated with CKD in JUMC Southwest Ethiopia, 2020

\begin{tabular}{|l|l|l|l|l|}
\hline Assumption & Variables & Hazard Ratio & Probability of Event & Sample Size (Event) \\
\hline Type I error=0.05 & HDL-C (>40 mg/dL) & 0.43 & 0.144 & $341(45)$ \\
power $=80 \%$ & LDL-C (<100 mg/dL) & 3.05 & 0.144 & $195(26)$ \\
withdrawal probability=0.I & HTN (Yes) & 2.42 & 0.1023 & $437(41)$ \\
\hline
\end{tabular}

Abbreviations: HDL-C, high density lipoprotein cholesterol; HTNLDL-C, low density lipoprotein cholesterol. 


\section{Results}

\section{Baseline Characteristics of Study Participants}

A total of 437 randomly selected newly-diagnosed DM patient's cards were reviewed. After excluding 32 patients with incomplete information, 405 patients were included in the final analyses.

The mean (SD) of age at the start of the study was 43.9 (15.8) years and males constituted $61.5 \%$ of study participants. Regarding residence, 242 (59.8\%) were urban dwellers. Besides, there is a high frequency of proteinuria, hypertension, diabetic retinopathy, and a history of AKI or cardiac disease at baseline among CKD cases compared to their counterparts (Table 2).

\section{Chronic Kidney Disease among Diabetic Patients}

The study participants were followed for a median follow-up time of 70 months $(\mathrm{IQR}=60.20-83.20)$. Of the total participants followed for a maximum of 89.80 months, $63(15.56 \%$;

Table 2 Socio-Demographic, Clinical and Physiologic Characteristics of DM Patients on Treatment at Jimma University Medical Center, Southwest Ethiopia, 2020

\begin{tabular}{|c|c|c|c|}
\hline Variables & $\begin{array}{l}\text { Censored } \\
(n=342)\end{array}$ & $\begin{array}{l}\text { Event=CKD } \\
(n=63)\end{array}$ & $\begin{array}{l}\text { Total } \\
(n=405)\end{array}$ \\
\hline \multicolumn{4}{|l|}{ Sex } \\
\hline Male & $205(59.94)$ & $44(69.84)$ & $249(61.48)$ \\
\hline Female & $137(40.06)$ & $19(30.16)$ & $156(38.52)$ \\
\hline \multicolumn{4}{|l|}{ Residence } \\
\hline Urban & $208(60.82)$ & $33(52.38)$ & $242(59.75)$ \\
\hline Rural & $134(39.18)$ & $30(47.62)$ & $163(40.25)$ \\
\hline \multicolumn{4}{|l|}{ Family history of DM } \\
\hline No & $246(71.92)$ & $47(74.60)$ & $293(72.35)$ \\
\hline Yes & $96(28.08)$ & $16(25.40)$ & $112(27.65)$ \\
\hline \multicolumn{4}{|l|}{ Type of DM } \\
\hline TIDM & $110(32.16)$ & $10(15.87)$ & $120(29.63)$ \\
\hline T2DM & $232(67.84)$ & $53(84.13)$ & $285(70.37)$ \\
\hline \multicolumn{4}{|l|}{ Type of treatment } \\
\hline $\mathrm{OHA}$ & $176(51.46)$ & $4 \mid(65.08)$ & $217(53.58)$ \\
\hline Insulin & III (32.46) & $11(17.46)$ & $122(30.12)$ \\
\hline Both & $55(16.08)$ & II (17.46) & $66(16.30)$ \\
\hline \multicolumn{4}{|l|}{ History of AKI } \\
\hline Yes & $49(14.33)$ & $40(63.49)$ & $89(21.98)$ \\
\hline \multicolumn{4}{|l|}{ Proteinuria } \\
\hline Positive & $46(13.45)$ & $44(69.84)$ & $90(22.23)$ \\
\hline
\end{tabular}

(Continued)
Table 2 (Continued).

\begin{tabular}{|c|c|c|c|}
\hline Variables & $\begin{array}{l}\text { Censored } \\
(n=342)\end{array}$ & $\begin{array}{l}\text { Event=CKD } \\
(n=63)\end{array}$ & $\begin{array}{l}\text { Total } \\
(n=405)\end{array}$ \\
\hline \multicolumn{4}{|l|}{ Total cholesterol (mg/dL) } \\
\hline Desirable & $227(66.37)$ & $23(36.51)$ & $250(61.73)$ \\
\hline Borderline & $58(16.96)$ & $16(25.40)$ & $74(18.27)$ \\
\hline High & $42(12.28)$ & $24(38.09)$ & $66(16.30)$ \\
\hline \multicolumn{4}{|l|}{ Triglyceride (md/dL) } \\
\hline Normal & 181 (52.92) & II (I7.46) & $192(47.41)$ \\
\hline Borderline & $56(16.37)$ & $23(36.51)$ & $79(19.51)$ \\
\hline High & $82(23.98)$ & $29(46.03)$ & III (27.4I) \\
\hline \multicolumn{4}{|l|}{ LDL-C (md/dL) } \\
\hline$<100$ & $231(67.54)$ & $21(33.33)$ & $234(57.78)$ \\
\hline$\geq 100$ & $109(31.87)$ & $42(66.67)$ & I5I (37.28) \\
\hline \multicolumn{4}{|l|}{ HDL-C (md/dL) } \\
\hline$\geq 40$ & $264(77.19)$ & $20(31.75)$ & $284(70.12)$ \\
\hline$<40$ & $51(14.91)$ & $43(68.25)$ & $94(23.21)$ \\
\hline \multicolumn{4}{|l|}{ BMI $\left(\mathrm{kg} / \mathrm{m}^{2}\right)$} \\
\hline$<18.5$ & $24(7.02)$ & $2(3.17)$ & $26(6.42)$ \\
\hline $18.5-24.9$ & $236(69.01)$ & $12(19.05)$ & $248(61.23)$ \\
\hline$\geq 25$ & $73(21.35)$ & $49(77.78)$ & $122(30.12)$ \\
\hline \multicolumn{4}{|l|}{ Hypertension } \\
\hline Yes & $142(4 \mid .52)$ & $53(84.13)$ & $195(48.15)$ \\
\hline \multicolumn{4}{|l|}{ Diabetic retinopathy } \\
\hline Yes & $51(14.91)$ & $30(47.62)$ & $81(20.00)$ \\
\hline \multicolumn{4}{|l|}{ Cardiovascular disease } \\
\hline Yes & $34(9.94)$ & $21(33.33)$ & $55(13.58)$ \\
\hline Age, mean (SD) & $42.7(15.37)$ & $50.1(16.80)$ & $\begin{array}{l}43.9 \\
(15.80)\end{array}$ \\
\hline SBP, mean (SD) & $\begin{array}{l}123.99 \\
(18.92)\end{array}$ & $135.7(21.50)$ & $\begin{array}{l}125.80 \\
(19.80)\end{array}$ \\
\hline DBP, median (IQR) & $80(70-90)$ & $85(70-90)$ & $80(70-90)$ \\
\hline Creatinine, median (IQR) & $\begin{array}{l}0.8(0.63- \\
0.98)\end{array}$ & $2.3(1.8-3.00)$ & $\begin{array}{l}0.85(0.67- \\
1.20)\end{array}$ \\
\hline
\end{tabular}

Notes: HDL-C, LDL-C, Total cholesterol, BMI, and Triglyceride had missing data. Complete case analysis and imputed model were fitted and complete case analysis was selected using AIC.

Abbreviations: AKI, acute kidney injury; BMI, body mass index; DM, diabetes mellitus; HDL-C, high density lipoprotein cholesterol; IQR, inter-quartile range; LDL-C, low density lipoprotein cholesterol; OHA, oral hypoglycemic agents; SD, standard deviation, Total cholesterol (desirable: <200, borderline high: 200-239, high: $\geq 240$ ), Triglyceride (normal: $<150$, borderline high: 150-199, high: $\geq 200$ ); TIDM, type one diabetes mellitus; T2DM, type two diabetes mellitus.

95\% $\mathrm{CI}=12.24-19.54)$ patients had developed $\mathrm{CKD}$ in 27,494.44 PM observations (Figure 1). The incidence density was 2.29/1,000 PM, with 95\% CI of 1.79-2.93 or 2.75 per 100 person year (PY) $(95 \% \mathrm{CI}=2.15-3.52)$. The cumulative survival probability of patients was 0.975 at 20 months, 0.937 at 40 months, 0.867 at 60 months, and 0.781 by the end of the study (Figure 2). The survival of DM patients was lower 


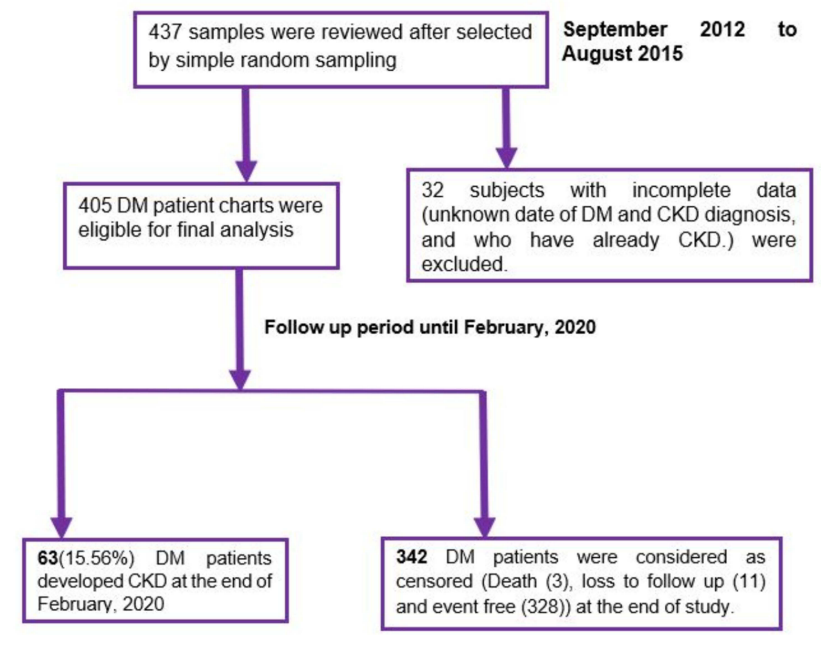

Figure I Flowchart of DM patients on treatment at Jimma university medical center, Southwest Ethiopia, 2012 to 2020.

Overall KM survival estimate for DM patients

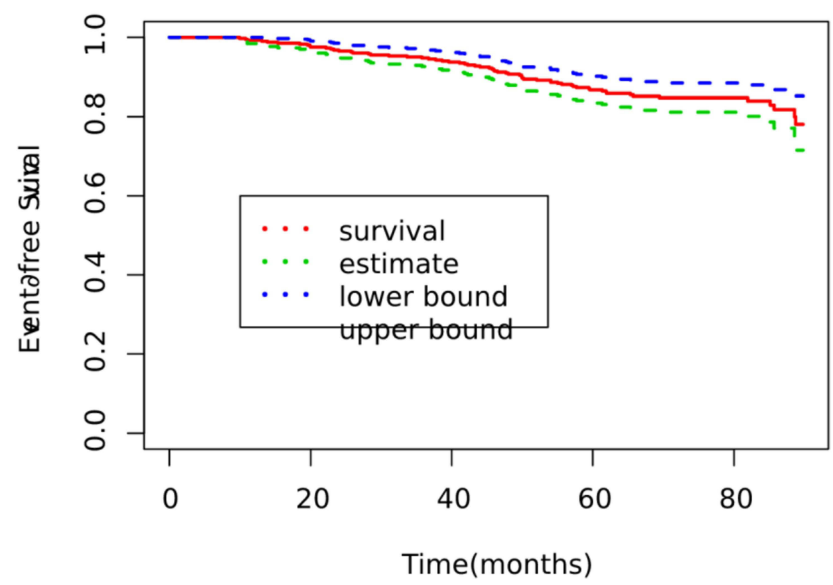

Figure 2 Overall Kaplan Meier of survival curves for DM patients on treatment at Jimma university medical center, Southwest Ethiopia, 2012 to 2020.

among patients with HTN compared with their counterparts (Figure 3).

\section{Predictors of CKD among Diabetic Patients}

The multivariable Cox-proportional hazard model (lowest AIC compared to all other model) was used to evaluate the effect of different factors on the risk of CKD. The tolerance for each covariate in the model was from 0.752 0.981 (Supplementary Table B), indicating an absence of multicollinearity. To manage the missing data, we applied sensitivity analysis to multiple imputations and a complete case analysis approach of missing data handling

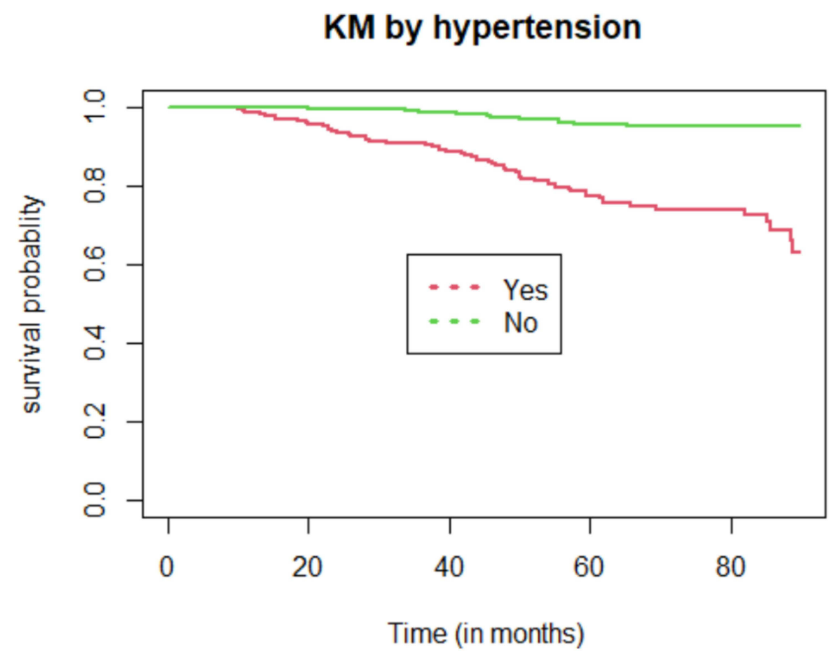

Figure 3 Kaplan-Meier of survival curves by HTN status for DM patients on treatment at Jimma university medical center, Southwest Ethiopia, 2012 to 2020.

mechanisms. The result showed no difference in parameter estimates under two methods. Complete case analysis was selected based on AIC $(7,150.39)$ compared with the imputed model. The $p$-value for global Schoenfeld residual test was 0.624 (Supplementary Table A), which indicates fulfillment of PH assumption. Goodness of fit of the model was assessed by Cox Snell residual plot. Cumulative hazard plot follows a straight line through the origin with slope one indicating the model is good (Supplementary Figure A). In the multivariable Cox regression, variables like sex, hypertension status, proteinuria at baseline, and HDL-C level were found to be independent predictors for CKD among DM patients (Table 3). The hazard of experiencing CKD is decreased by almost half among female patients compared to males. The hazard of developing CKD is 2.85-times higher among DM patients with positive proteinuria as compared to their counterparts. The risk of CKD for patients who have hypertension at baseline was 2.31-times higher than that of patients who have no hypertension. After adjusting for other variables in the model, the hazard of experiencing CKD was 3.19-times higher for DM patients with HDL-C $<40 \mathrm{mg} / \mathrm{dL}$ as compared to those patients with HDL-C $\geq 40 \mathrm{mg} / \mathrm{dL}$.

\section{Discussion}

The current study investigated the incidence and predictors of CKD among T1DM and T2DM patients at Jimma university medical center, Southwest Ethiopia. Factors like sex, proteinuria, HTN, and HDL-C were found to be significantly associated with risk of CKD. 
Table 3 Multivariable Cox Regression Results for Predictors of CKD among DM Patients on Treatment at Jimma University Medical Center, Southwest Ethiopia, 2020

\begin{tabular}{|c|c|c|c|}
\hline Variables & Categories & CHR $[95 \% \mathrm{Cl}]$ & AHR $[95 \% \mathrm{Cl}]$ \\
\hline Age & $\begin{array}{l}<65 \\
\geq 65\end{array}$ & $\begin{array}{l}\mathrm{I} \\
\mathrm{I} .97[1.01,3.72]\end{array}$ & $\begin{array}{l}\text { I } \\
1.26[0.61,2.49]\end{array}$ \\
\hline Sex & $\begin{array}{l}\text { Male } \\
\text { Female }\end{array}$ & $\begin{array}{l}\text { I } \\
0.57[0.31,1.02]\end{array}$ & $\begin{array}{l}\text { I } \\
0.51[0.27,0.94]^{* *}\end{array}$ \\
\hline Proteinuria & $\begin{array}{l}\text { Negative } \\
\text { Positive }\end{array}$ & $\begin{array}{l}\text { I } \\
5.86[3.35,10.65]\end{array}$ & $\begin{array}{l}\text { I } \\
2.85[1.48,5.55] * * *\end{array}$ \\
\hline AKI & $\begin{array}{l}\text { No } \\
\text { Yes }\end{array}$ & $\begin{array}{l}\text { I } \\
4.22[2.43,7.48]\end{array}$ & $\begin{array}{l}\text { I } \\
\text { I.8I }[0.92,3.54]\end{array}$ \\
\hline HTN & $\begin{array}{l}\text { No } \\
\text { Yes }\end{array}$ & $\begin{array}{l}\text { I } \\
4.65[2.38,9.75]\end{array}$ & $\begin{array}{l}\text { I } \\
2.31[1.03,5.56]^{* *}\end{array}$ \\
\hline DR & $\begin{array}{l}\text { No } \\
\text { Yes }\end{array}$ & I.84 [1.08, 3.09] & $\begin{array}{l}\text { I } \\
1.23[0.52,1.65]\end{array}$ \\
\hline CVD & $\begin{array}{l}\text { No } \\
\text { Yes }\end{array}$ & I. $18[0.65,2.08]$ & $\begin{array}{l}\text { I } \\
1.12[0.29,1.96]\end{array}$ \\
\hline BMI $\left(\mathrm{kg} / \mathrm{m}^{2}\right)$ & $\begin{array}{l}<18.5 \\
18.5-24.9 \\
\geq 25\end{array}$ & $\begin{array}{l}\mathrm{I} \\
0.85[0.20,5.26] \\
5.17[1.33,30.57]\end{array}$ & $\begin{array}{l}\text { I } \\
0.55[0.12,3.62] \\
1.80[0.42,11.5 I]\end{array}$ \\
\hline HDL-C (md/dL) & $\begin{array}{l}\geq 40 \\
<40\end{array}$ & $\begin{array}{l}\text { I } \\
4.71[2.72,8.40]\end{array}$ & $\begin{array}{l}\text { I } \\
3.19[1.73,5.98] * * *\end{array}$ \\
\hline LDL-C (md/dL) & $\begin{array}{l}<100 \\
\geq 100\end{array}$ & $\begin{array}{l}\text { I } \\
3.93[2.17,7.35]\end{array}$ & $\begin{array}{l}\text { I } \\
1.29[0.69,2.49]\end{array}$ \\
\hline
\end{tabular}

Notes: **Indicates $P$-value $<0.01$ and $* * * P$-value $<0.001$.

Abbreviations: AKI, acute kidney injury; BMI, body mass index; CVD, cardiovascular disease; DR, diabetic retinopathy; HDL-C, high density lipoprotein cholesterol; HTN, hypertension; LDL-C, low density lipoprotein cholesterol.

In our study, $15.56 \%$ of the study participants had developed CKD with the incidence density of 2.291 per 1,000 PM or 2.75 per 100-person year (PY) of observation. This was higher than studies done in Korea $(12.1 \%)^{31}$ and The Netherlands (12.18 per 1,000 PY). ${ }^{32}$ This difference could be because the age of onset of T2DM is decreasing, allowing patients to have a longer duration of diabetes to develop $\mathrm{CKD} .{ }^{33}$ In addition, the black race is associated with a greater rate of GFR decline, ${ }^{34}$ which may be due to the presence of apolipoprotein L1 highrisk genotype for renal impairment in black race. ${ }^{35}$ On the other hand, the incidence of CKD in the current study was lower than studies done in Australia (7.4 per $100 \mathrm{PY}){ }^{36}$ Morocco (34.7\%), ${ }^{37}$ and the UK, with $29 \%$ cumulative incidence. ${ }^{38}$ This could be due to the higher life expectancy of the Australian (83.9 years), UK (81.7 years), and Moroccon (77.4 years) population compared to the Ethiopian (67.7 years) population. ${ }^{39}$ After the age of 30 years, GFR progressively declines at an average rate of
$8 \mathrm{~mL} / \mathrm{min} / 1.73 \mathrm{~m}^{2}$ per decade. ${ }^{40}$ This might be due to structural and functional changes of the kidney in older patients. ${ }^{41,42}$

In our study, females were found to have a lower risk of developing CKD compared to male patients. This finding is congruent with different prospective studies around the world. $^{43,44}$ The reason might be due to estrogen, the hormone that is absent in males. The hormone can improve glycemic control and lipid metabolism which eventually decreases the risk of CKD in DM patients. ${ }^{45}$ Estrogen from the onset of diabetes can also reduce albuminuria, glomerulosclerosis, and tubulointerstitial fibrosis, suggesting that estrogen may be reno-protective. ${ }^{46,47}$ However, the result of the current study is incongruent with studies done in the $\mathrm{US}^{48}$ and Spain. ${ }^{19}$ Therefore, taking female sex as a protective or risk for CKD in DM patients would be difficult and indicates there is a need of further investigation about this issue. The hazard of developing CKD is higher among DM patients with positive proteinuria as compared to their counterparts. Albumin is the 
main protein filtered through the glomerular membrane, and retrieved by proximal tubule. ${ }^{49}$ Proteinuria is caused by either functional or structural alterations of glomerular filtration or proximal tubule dysfunction. ${ }^{50}$ A protein induced interstitial inflammation and fibrosis, ${ }^{51}$ and proximal tubular cells apoptosis and dysfunctional autophagy are some of the mechanisms which lead to renal injury. ${ }^{52,53}$

This finding is in agreement with studies done in Ethiopia, ${ }^{24}$ Spain, ${ }^{19}$ and Japan. ${ }^{54}$ The Indians Pima study among 983 patients with T2DM found a 1.71-fold increase of incident CKD for each doubling of albumin-to-creatinine ratio. ${ }^{55}$ There are other studies which found proteinuria as an independent predictor of ESRD. ${ }^{56,57}$ This might be due to the crucial role of proteinuria in accelerating kidney disease progression to ESRD, promoting loss of kidney function and scarring. ${ }^{58,59}$

According to our finding, the hazard of experiencing CKD is much higher among DM patients who had HTN compared to their counterparts. This result indicates that controlling blood pressure among DM patients has a crucial role in decreasing the risk of CKD. ${ }^{60,61}$ This result is consistent with previous studies in Ethiopia, ${ }^{24}$ Spain, ${ }^{19}$ and China. ${ }^{23}$ The possible reason could be that HTN can affect endothelial cell structure and functioning that leads to enhanced abnormal growth of endothelial cells and vasoconstriction. This change to the endothelium leads to development of glomerulosclerosis, which predisposes patients to CKD. ${ }^{62}$

Patients with $<40 \mathrm{mg} / \mathrm{dL}$ HDL-C had higher risks of developing CKD compared to their counterparts. This result was supported by studies conducted in Ethiopia ${ }^{24}$ and other studies done by Muntner et $\mathrm{al}^{20}$ and Bowe et al. ${ }^{21}$ Biologically, HDL-C transports fats (lipids) away from the artery wall to the liver. This eventually reduces accumulation of fats and atherosclerosis within the arterial wall. Besides, it protects the inner wall of the arteries from damage so this reduces the risk of vascular complications of DM including CKD. ${ }^{63}$ Hence, patients with a low level of HDL-C might lack this function of HDL-C and become at higher risk of CKD.

The clinical importance of findings of this study was to provide information for health professionals about the incidence and factors that are associated with the risk of CKD and to act on them to minimize the risk and maximize their effort on its prevention. The public health importance of this study is to prevent economic loss associated with dialysis and transplantation in ESRD by identifying the variable most significantly associated with CKD.

\section{Strengths and Limitations of the Study}

Though our study has the strength to estimate the incidence of CKD over a longer follow-up period, it is not free from limitations. The nature of the study relies on knowing the exact time of onset of DM and CKD. This study used physicians' decisions to define or diagnose CKD which alone might not be sufficiently reliable. In addition, the secondary nature of data prevented the inclusion of all possible predictors that affect CKD. The study also assumed all the CKD are caused by DM and may overestimate the rate of $\mathrm{CKD}$. In our study area $\mathrm{HbA} 1 \mathrm{c}$ were not done for follow-up, leading to the use of fasting blood sugar.

\section{Conclusion}

In the current study, the ncidence of CKD was relatively high compared with previous similar studies in Ethiopia. Female sex was found to be a protective factor of CKD, while, having hypertension, positive proteinuria at baseline and HDL-C $<40 \mathrm{mg} / \mathrm{dL}$ were found to be risk factors for CKD among diabetic patients. In the light of these findings, we recommend health professionals to give more attention to T1DM and T2DM patients with proteinuria, HDL-C $<40 \mathrm{mg}$ / $\mathrm{dL}$, and hypertension.

\section{Abbreviations}

AHR, adjusted hazard ratio; AKI, acute kidney injury; $\mathrm{BMI}$, body mass index; $\mathrm{CI}$, confidence interval; $\mathrm{CHR}$, crude hazard ratio; CKD, chronic kidney disease; DBP, diastolic blood pressure; DIC, deviance information criteria; DM, diabetes mellitus; ESRD, end stage renal disease; FBS, fasting blood sugar; GFR, glomerular filtration rate; HbAlc, glycated hemoglobin; HDL-C, high-density lipoprotein cholesterol; HTN, hypertension; $\mathrm{Kg} / \mathrm{m}^{2}$, kilogram per square meters; KM, Kaplan-Meier; LDL-C, lowdensity lipoprotein cholesterol; MCMC, Markov Chain Monte Carlo; OHA, oral hypoglycemic agent; PHA, proportional hazard assumption; PY, person years; SBP, systolic blood pressure; T1DM, type one diabetes mellitus; T2DM, type two diabetes mellitus; TG; triglyceride; USA, United States of America.

\section{Data Sharing Statement}

Data will be available from the corresponding author upon request. 


\section{Ethical Approval and Consent to Participate}

The Institutional Review Board of the Mettu University approved and waived the requirement of informed consent for reviewing patient medical charts for the current study due to the retrospective nature of the study. Additionally, permission was obtained from the medical director of the hospitals by showing the waiver/Ethical letter issued by Mettu University in order to access medical records of patients. Data confidentiality was kept during all phases of research activities and held on secured password protected system. The study was in compliance with the Declaration of Helsinki.

\section{Acknowledgments}

Our heartfelt gratitude goes to the Jimma University Medical Center and Mettu University for support by all necessary services. Additionally, we appreciate the support from Hospital administrations and data collector.

\section{Author Contributions}

All authors made a significant contribution to the work reported, whether that is in the conception, study design, execution, acquisition of data, analysis and interpretation, or in all these areas; took part in drafting, revising, or critically reviewing the article; gave final approval of the version to be published; have agreed on the journal to which the article has been submitted; and agree to be accountable for all aspects of the work.

\section{Funding}

The Mettu University has covered the costs of data collectors and supervisors per diem. However, the University had no role in study design, data collections, and analysis, decision to publish, or preparation of the manuscript.

\section{Disclosure}

The authors report no conflicts of interest in this work.

\section{References}

1. ADA. Classification and diagnosis of diabetes: standards of medical care in diabetes-2018. Diabetes Care. 2018;41(Supplement 1):S13S27. doi:10.2337/dc18-S002

2. Inernational Diabetes federation. Diabetes Atlas. 9th ed. 2019.

3. Rao Kondapally Seshasai S, Kaptoge S, Thompson A, et al. Diabetes mellitus, fasting glucose, and risk of cause-specific death. $N$ Engl $J$ Med. 2011;364(9):829-841.

4. Reutens AT. Epidemiology of diabetic kidney disease. Med Clinics. 2013;97(1):1-18.
5. De Cosmo S, Viazzi F, Piscitelli P, et al. Blood pressure status and the incidence of diabetic kidney disease in patients with hypertension and type 2 diabetes. J Hypertens. 2016;34(10):2090-2098. doi:10.1097/ HJH.0000000000001045

6. Gallagher H, Suckling R. Diabetic nephropathy: where are we on the journey from pathophysiology to treatment?. Diabetes Obe Metab. 2016;18(7):641-647. doi:10.1111/dom.12630

7. Eknoyan G, Lameire N, Eckardt K, et al. KDIGO 2012 clinical practice guideline for the evaluation and management of chronic kidney disease. Kidney Int. 2013;3(1):5-14.

8. Wang H, Naghavi M, Allen C, et al. Global, regional, and national life expectancy, all-cause mortality, and cause-specific mortality for 249 causes of death, 1980-2015: a systematic analysis for the Global Burden of Disease Study 2015. Lancet. 2016;388(10053):1459-1544.

9. Jha V, Garcia-Garcia G, Iseki K, et al. Chronic kidney disease: global dimension and perspectives. Lancet. 2013;382(9888):260-272. doi:10.1016/S0140-6736(13)60687-X

10. Wagnew F, Eshetie S, Kibret GD, et al. Diabetic nephropathy and hypertension in diabetes patients of sub-Saharan countries: a systematic review and meta-analysis. BMC Res Notes. 2018;11 (1):565. doi:10.1186/s13104-018-3670-5

11. Fiseha T, Kassim M, Yemane T. Prevalence of chronic kidney disease and associated risk factors among diabetic patients in southern Ethiopia. Am J Health Res. 2014;2(4):216-221. doi:10.11648/j. ajhr.20140204.28

12. Damtie S, Biadgo B, Baynes HW, et al. Chronic kidney disease and associated risk factors assessment among diabetes mellitus patients at a Tertiary Hospital, Northwest Ethiopia. Ethiop $J$ Health Sci. 2018;28:6.

13. Go A, Chertow G, Fan D. Chronic kidney disease and the risks of death, cardiovascular events, and hospitalization. J Vasc Surg. 2005;41(1):177. doi:10.1016/j.jvs.2004.10.020

14. Roglic G. WHO Global report on diabetes: a summary. Int $J$ Noncommun Dis. 2016;1(1):3. doi:10.4103/2468-8827.184853

15. Neuen BL, Chadban SJ, Demaio AR, Johnson DW, Perkovic V. Chronic kidney disease and the global NCDs agenda. BMJ Global Health. 2017;2(2):e000380. doi:10.1136/bmjgh-2017-000380

16. Abraham G. The Challenges of Renal Replacement Therapy in Asia. Nature Publishing Group; 2008.

17. Rajapurkar MM, John GT, Kirpalani AL, et al. What do we know about chronic kidney disease in India: first report of the Indian CKD registry. BMC Nephrol. 2012;13(1):10. doi:10.1186/1471-2369-13-10

18. Liyanage $\mathrm{T}$, Ninomiya $\mathrm{T}$, Jha $\mathrm{V}$, et al. Worldwide access to treatment for end-stage kidney disease: a systematic review. Lancet. 2015;385 (9981):1975-1982. doi:10.1016/S0140-6736(14)61601-9

19. Salinero-Fort MA, San Andrés-Rebollo FJ, de Burgos-Lunar C, et al. Five-year incidence of chronic kidney disease (stage 3-5) and associated risk factors in a Spanish cohort: the MADIABETES study. PLoS One. 2015;10(4):e0122030. doi:10.1371/journal.pone. 0122030

20. Muntner P, Coresh J, Smith JC, Eckfeldt J, Klag MJ. Plasma lipids and risk of developing renal dysfunction: the atherosclerosis risk in communities study. Kidney Int. 2000;58(1):293-301. doi:10.1046/ j.1523-1755.2000.00165.X

21. Bowe B, Xie Y, Xian H, Balasubramanian S, Al-Aly Z. Low levels of high-density lipoprotein cholesterol increase the risk of incident kidney disease and its progression. Kidney Int. 2016;89(4):886-896. doi:10.1016/j.kint.2015.12.034

22. Geletu AH, Teferra AS, Sisay MM, Teshome DF. Incidence and predictors of chronic kidney diseases among type 2 diabetes mellitus patients at St. Paul's Hospital, Addis Ababa, Ethiopia. BMC Res Notes. 2018;11(1):532.

23. Luk AOY, So WY, Ma RCW, et al. Metabolic syndrome predicts new onset of chronic kidney disease in 5829 patients with Type 2 diabetes: a 5 -year prospective analysis of the Hong Kong Diabetes Registry. Diabetes Care. 2008;31(12):2357-2361. doi:10.2337/dc08-0971 
24. Wolde HF, Atsedeweyen A, Jember A, et al. Predictors of vascular complications among type 2 diabetes mellitus patients at University of Gondar Referral Hospital: a retrospective follow-up study. BMC Endocr Disord. 2018;18(1):52. doi:10.1186/s12902-018-0280-0

25. Wilkinson CP, Ferris FL 3rd Klein RE, et al. Proposed international clinical diabetic retinopathy and diabetic macular edema disease severity scales. Ophthalmology. 2003;110(9):1677-1682. doi:10.10 16/S0161-6420(03)00475-5

26. WHO. Physical Status: The Use and Interpretation of Anthropometry. Report of a WHO Expert Committee. Vol. 854. Geneva: World Health Organization technical report series; 1995:1-452.

27. WHO. Regional Office for the Western Pacific. Noncommunicable Disease Education Manual for Primary Health Care Professionals and Patients. Manila: WHO Regional Office for the Western Pacific; 2017. Available from: https://apps.who.int/iris/handle/10665/254746. Accessed October 19, 2021.

28. Grundy SM. Third report of the national cholesterol education program (NCEP) expert panel on detection, evaluation, and treatment of high blood cholesterol in adults (Adult Treatment Panel III) final report. Circulation. 2002;106:3143-3421.

29. Patient Care \& Health Information. Tests \& procedures: Mayo Foundation for Medical Education and Research ((MFMER); 2019 Available from: https://www.mayoclinic.org/tests-procedures/choles terol-test/about/pac-20384601. Accessed October 19, 2021.

30. Schoenfeld DA. Sample-size formula for the proportional-hazards regression model. Biometrics. 1983;39(2):499-503. doi:10.2307/ 2531021

31. Kim WJ, Kim SS, Bae MJ, et al. High-normal serum uric acid predicts the development of chronic kidney disease in patients with type 2 diabetes mellitus and preserved kidney function. J Diabetes Compl. 2014;28(2):130-134. doi:10.1016/j.jdiacomp.2013.11.006

32. van Blijderveen JC, Straus SM, Zietse R, Stricker BH, Sturkenboom MC, Verhamme KM. A population-based study on the prevalence and incidence of chronic kidney disease in the Netherlands. Int Urol Nephrol. 2014;46(3):583-592. doi:10.1007/ s11255-013-0563-3

33. Koopman RJ, Mainous AG, Diaz VA, Geesey ME. Changes in age at diagnosis of type 2 diabetes mellitus in the United States, 1988 to 2000. Ann Fam Med. 2005;3(1):60-63. doi:10.1370/afm.214

34. Derose SF, Rutkowski MP, Crooks PW, et al. Racial differences in estimated GFR decline, ESRD, and mortality in an integrated health system. Am J Kidney Dis. 2013;62(2):236-244. doi:10.1053/j. ajkd.2013.01.019

35. Grams ME, Rebholz CM, Chen Y, et al. Race, APOL1 risk, and eGFR decline in the general population. J Am Soc Nephrol. 2016;27 (9):2842-2850. doi:10.1681/ASN.2015070763

36. Schimke K, Chubb SA, Davis WA, Davis TM. Helicobacter pylori cytotoxin-associated gene-A antibodies do not predict complications or death in type 2 diabetes: the Fremantle Diabetes Study. Atherosclerosis. 2010;212(1):321-326. doi:10.1016/j.atherosclerosis. 2010.05.021

37. Bentata Y, Haddiya I, Latrech H, Serraj K, Abouqal R. Progression of diabetic nephropathy, risk of end-stage renal disease and mortality in patients with type-1 diabetes. Saudi J Kidney Dis Transplant. 2013;24(2):392. doi:10.4103/1319-2442.109617

38. Retnakaran R, Cull CA, Thorne KI, Adler AI, Holman RR. Risk factors for renal dysfunction in type 2 diabetes: UK Prospective Diabetes Study 74. Diabetes. 2006;55(6):1832-1839. doi:10.2337/db05-1620

39. Worldometer. Life Expectancy of the World Population, Countries ranked by life expectancy; 2020. Available from: https://www.worldometers.info/ demographics/life-expectancy/. Accessed October 19, 2021.

40. Coresh J, Astor BC, Greene T, Eknoyan G, Levey AS. Prevalence of chronic kidney disease and decreased kidney function in the adult US population: third National Health and Nutrition Examination Survey. Am J Kidney Dis. 2003;41(1):1-12. doi:10.1053/ajkd.2003.50007
41. Hayslett JP, Kashgarian M, Epstein FH. Functional correlates of compensatory renal hypertrophy. J Clin Invest. 1968;47(4):774-782. doi:10.1172/JCI105772

42. Thomson SC, Vallon V, Blantz RC. Kidney function in early diabetes: the tubular hypothesis of glomerular filtration. Am J Physiol Renal Physio. 2004;286(1):F8-F15. doi:10.1152/ajprenal.00208.2003

43. Lipworth L, Mumma MT, Cavanaugh KL, et al. Incidence and predictors of end stage renal disease among low-income blacks and whites. PLoS One. 2012;7(10):e48407. doi:10.1371/journal.pone.0048407

44. Silbiger S, Neugarten J. Gender and human chronic renal disease. Gend Med. 2008;5:S3-S10. doi:10.1016/j.genm.2008.03.002

45. Ferrara A, Karter AJ, Ackerson LM, Liu JY, Selby JV. Hormone replacement therapy is associated with better glycemic control in women with type 2 diabetes: the Northern California Kaiser Permanente Diabetes Registry. Diabetes Care. 2001;24 (7):1144-1150. doi:10.2337/diacare.24.7.1144

46. Dixon A, Wells CC, Singh S, Babayan R, Maric C. Renoprotective effects of a selective estrogen receptor modulator, raloxifene, in an animal model of diabetic nephropathy. Am J Nephrol. 2007;27 (2):120-128. doi:10.1159/000099837

47. Mankhey RW, Wells CC, Bhatti F, Maric C. 17 $\beta$-Estradiol supplementation reduces tubulointerstitial fibrosis by increasing MMP activity in the diabetic kidney. Am J Physiol Regul Int Comp Physiol. 2007;292(2):R769-R77. doi:10.1152/ajpregu.00375.2006

48. Yu MK, Katon W, Young BA. Associations between sex and incident chronic kidney disease in a prospective diabetic cohort. Nephrology. 2015;20(7):451-458. doi:10.1111/nep.12468

49. Dickson LE, Wagner MC, Sandoval RM, Molitoris BA. The proximal tubule and albuminuria: really! J Am Soc Nephrol. 2014;25 (3):443-453.

50. Jefferson J, Shankland S, Pichler R. Proteinuria in diabetic kidney disease: a mechanistic viewpoint. Kidney Int. 2008;74(1):22-36. doi:10.1038/ki.2008.128

51. Kuusniemi A-M, Lapatto R, Holmberg C, Karikoski R, Rapola J, Jalanko H. Kidneys with heavy proteinuria show fibrosis, inflammation, and oxidative stress, but no tubular phenotypic change. Kidney Int. 2005;68(1):121-132. doi:10.1111/j.1523-1755.2005.00386.x

52. Tejera N, Gómez-Garre D, Lázaro A, et al. Persistent proteinuria up-regulates angiotensin II type 2 receptor and induces apoptosis in proximal tubular cells. Am J Pathol. 2004;164(5):1817-1826. doi:10.1016/S0002-9440(10)63740-6

53. Nolin AC, Mulhern RM, Panchenko MV, et al. Proteinuria causes dysfunctional autophagy in the proximal tubule. Am J Physiol Renal Physiol. 2016;311(6):F1271-F9. doi:10.1152/ajprenal.00125.2016

54. Jiang G, Luk AOY, Tam CHT, et al. Progression of diabetic kidney disease and trajectory of kidney function decline in Chinese patients with Type 2 diabetes. Kidney Int. 2019;95(1):178-187. doi:10.1016/j. kint.2018.08.026

55. Pavkov ME, Knowler WC, Hanson RL, Bennett PH, Nelson RG. Predictive power of sequential measures of albuminuria for progression to ESRD or death in Pima Indians with type 2 diabetes. Am J Kidney Dis. 2008;51(5):759-766. doi:10.1053/j.ajkd.2008.01.011

56. Van Der Velde M, Matsushita K, Coresh J, et al. Lower estimated glomerular filtration rate and higher albuminuria are associated with all-cause and cardiovascular mortality. A Collaborative Meta-Analysis of High-Risk Population Cohorts. Kidney Int. 2011;79(12):1341-1352.

57. Gansevoort RT, Matsushita K, van der Velde M, et al. Lower estimated GFR and higher albuminuria are associated with adverse kidney outcomes in both general and high-risk populations: a collaborative meta-analysis of general and high-risk population cohorts. Kidney Int. 2011;80(1):93. doi:10.1038/ki.2010.531

58. He C, Imai M, Song H, Quigg RJ, Tomlinson S. Complement inhibitors targeted to the proximal tubule prevent injury in experimental nephrotic syndrome and demonstrate a key role for C5b-9. J Immunol. 2005;174 (9):5750-5757. doi:10.4049/jimmunol.174.9.5750 
59. Cravedi P, Remuzzi G. Pathophysiology of proteinuria and its value as an outcome measure in chronic kidney disease. $\mathrm{Br} \mathrm{J}$ Clin Pharmacol. 2013;76(4):516-523.

60. Krishnan SM, Ling YH, Huuskes BM, et al. Pharmacological inhibition of the NLRP3 inflammasome reduces blood pressure, renal damage, and dysfunction in salt-sensitive hypertension. Cardiovasc Res. 2019;115(4):776-787. doi:10.1093/cvr/cvy252

61. Soto K, Gómez-Garre D, Largo R, et al. Tight blood pressure control decreases apoptosis during renal damage. Kidney Int. 2004;65 (3):811-822. doi:10.1111/j.1523-1755.2004.00455.x
62. Goligorsky MS, Chen J, Brodsky S. Workshop: endothelial cell dysfunction leading to diabetic nephropathy: focus on nitric oxide. Hypertension. 2001;37(2):744-748. doi:10.1161/01.HYP.37.2.744

63. Link JJ, Rohatgi A, de Lemos JA. HDL cholesterol: physiology, pathophysiology, and management. Curr Probl Cardiol. 2007;32 (5):268-314. doi:10.1016/j.cpcardiol.2007.01.004

\section{Publish your work in this journal}

Diabetes, Metabolic Syndrome and Obesity: Targets and Therapy is an international, peer-reviewed open-access journal committed to the rapid publication of the latest laboratory and clinical findings in the fields of diabetes, metabolic syndrome and obesity research. Original research, review, case reports, hypothesis formation, expert opinion and commentaries are all considered for publication. The manuscript management system is completely online and includes a very quick and fair peer-review system, which is all easy to use. Visit http://www.dovepress.com/testimonials.php to read real quotes from published authors. 